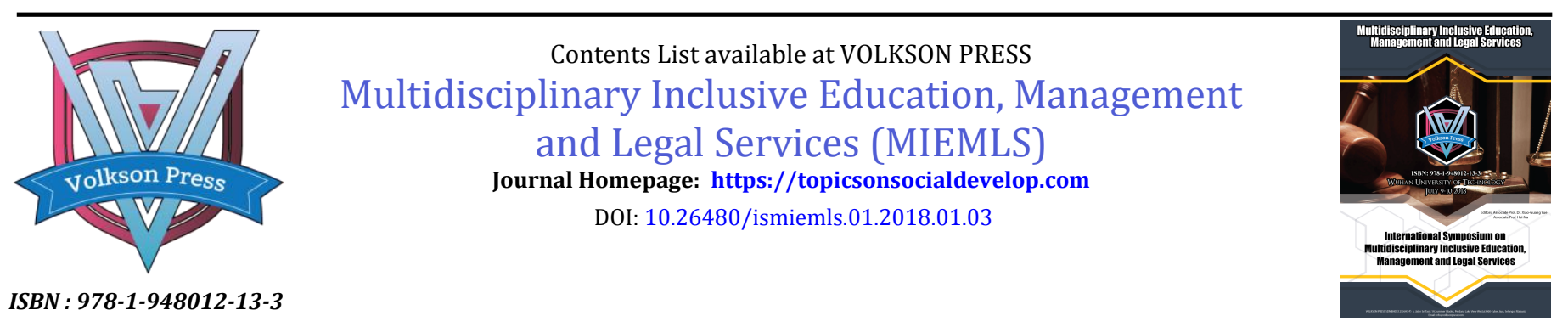

\title{
THE DESIGN AND IMPLEMENT OF MEDICAL X-RAY MACHINE PRACTICE COURSE
}

\author{
Feng Bohua ${ }^{1}$, Peng Liufen ${ }^{1}$, Wang Bo ${ }^{2}$, Liu Hua ${ }^{1}$, Liu Shijun ${ }^{1}$, Ruan Ping ${ }^{*}$ \\ 1 Department of biomedical engineering, college of medical information engineering, Guangdong pharmaceutical University, Guangzhou higher \\ education mega Center, Guangzhou, P.R. China \\ ${ }^{2}$ The first affiliated hospital of Guangdong pharmaceutical University \\ *Corresponding Author Email: tfengbh@gdpu.edu.cn
}

This is an open access article distributed under the Creative Commons Attribution License, which permits unrestricted use, distribution, and reproduction in any medium, provided the original work is properly cited.

\section{ARTICLE DETAILS}

Article History:

Received 26 June 2018

Accepted 2 July 2018

Available online 1 August 2018

\section{ABSTRACT}

Medical x-ray equipment course is a compulsory course for medical imaging engineering specialty. This paper is aimed to explore the training model of medical imaging engineering practice course under the emerging engineering education (3E) concept. The teaching reform goal of the course is to integrate theoretical knowledge and practical skills, and to upgrade teaching quality and training model. Under the practical demand oriented, teaching content is integrated, furthermore course lecturers and medical imaging experts are organized together effectively, which enhance theoretical and practical teaching effect. With strict process management and assessment methods, benign interactions between teaching and learning are constructed.

\section{KEYWORDS}

X-ray machine, emerging engineering education, teaching reform.

\section{INTRODUCTION}

After the emerging engineering education (3E) concept is put forward, demond of reform of engineering teaching process has become a consensus during the higher education [1,2]. This $3 \mathrm{E}$ is based on the new economy and new industry demonds. We need to establish innovative, comprehensive, full cycle engineering education concept. A new engineering training model combined new engineering and traditional engineering should be constructed. It is considered that the $3 \mathrm{E}$ concept is useful to establish and improve the China characteristics of engineering education system, and nowadays engineering education is moving forward to build a more powerful engineering education system $[3,4]$

The teaching reform on medical X-ray machine and CT imaging equipment practical training model is based on the combination of theory and practice teaching, which is also the vitality and attraction of this course. In order to meet the needs of actual equipment and skills, it is crucial to improve the level of practice teaching, which highlight the medical engineering integration characteristics during students training. Those are also the inevitable requirements for the construction of $3 \mathrm{E}$.

\section{METHODS}

(1) The construction of teaching team is strengthening to build the management system of practice bases. A perfect organization and management system is the primary premise of building a good practice base [5]. The practice bases are jointly managed by college and hospitals, meanwhile managements of the students are strengthened to guarantee the quality of the teaching. (2) Scientific and effective rules are the important premise of guaranteeing the quality and effect of teaching, and it is also the foundation to ensure the standardized operation of teaching. The construction of practice courses has been developed to clarify the purposes of teaching. And the requirements and standards are regulated to ensure improving the quality of practice teaching. (3) A unified teaching and practice plan should be compiled and strictly implemented. These plans are based on the requirements of the syllabus, combined with the actual requirements of the industry and the actual situation of the major.
The distribution of content and time should be appropriately arranged. For example, according to the classification of medical image equipments, reasonable students practice rotation plan should be posted. (4) Teachers from the outside school are invited to our practice base to guide students' practice. Those medical equipment engineers, medical doctors are more familiar with the whole industry chain including research \& development, customer service, operation and maintenance. Therefore, these teachers with technical positions are suitable to be part-time teachers and are arranged to training college students. (5) To assess the performance of the classroom teaching, the teacher's teamwork and cooperation are to be carried out. The form of examination is a written test and practice operation assessment. Test questions contain vital theoretical knowledge, practical training tasks comprehension and analysis.

\section{RESULTS AND DISCUSSION}

The initial goal of this teaching reform in the course is that specialty knowledge should be well understood by students, meanwhile the effectiveness of practical teaching should be achieved. And this goal is required by ascending the teaching quality and upgrading training model level. The purpose is to enable students to master the medical imaging principles of X-ray machines, the structural features of medical imaging equipment, the general circuit module principle and characteristics, and the components principles of CT, CR, DR, DSA. At the same time, it is necessary to make the students master the basic requirements of practical aspects such as fault identification, processing methods, equipment operation methods and so on.

In accordance with the foregoing organization methods and evaluation approaches, we have continuously made certain new progress in recent years. More than 222 students from level 2011 to 2014 in department of biomedical engineering have carried out fruitful practice training in the affiliated hospital of our university and the second people's hospital of Guangdong province. In this study, the WeChat online survey and paper questionnaires were used to get the experience data both of teaching and internship process. And 54 students in level 2012 and 46 students in level 2014 were extracted as statistical samples. The effective samples of those 
100 students were taken as the analysis basis. The specific results and problems are discussed as follows:

\subsection{The specific results demonstrate teaching reform plan is satisfied to actual demands}

Engineering training should be oriented to the needs of society with the background of the actual project training. For example, from year 2015 to 2017, a few of undergraduates have work into hospital's medical imaging related departments. In our findings, 54 persons are willing to carry out professional development in public or private hospitals, accounting for $54 \%$ of the samples surveyed. Some undergraduates obtain the chances to continue researching in the field of medical imaging technology in postgraduate colleges. As shown in Table 1, persons numbers of actual onboarding enterprises are compared with their original job expectations, we find that the engineering characteristics students mostly worked in the field of medical imaging equipment production, operation and services industry chain, which proportion is up to $69.6 \%$. Persons numbers of actual onboarding hospital are conformed to the expected data, reflecting the professional training of students are helpful to make them successfully enter the hospital medical department, where engaged in imaging equipment maintenance, operation, management and other work. As applied undergraduate majors, the persons numbers of actual onboarding institutions such as technical supervision and research institutes are account for $4.8 \%$, indicating that students' academic opportunities for further education have been improved. In the overall data of the actual occupation development, the number distribution is shown as pyramidal shape, which is more consistent with the training objectives and requirements of the professional and curriculum system.

Table 1: Persons numbers of actual onboarding enterprises compared with original

\begin{tabular}{|lccc|}
\hline Types & Person-time & expectation numbers / total \% & onboarding numbers / total \% \\
\hline Enterprise & 58 & 26.7 & 69.6 \\
\hline Hospitals & 64 & 29.5 & 25.6 \\
\hline Scientific institute & 17 & 7.8 & 1.6 \\
\hline Others & 18 & 8.3 & 3.2 \\
\hline
\end{tabular}

3.2

\section{Highlight teaching contents should be integrated}

The medical X-ray machine theory teaching should be pay more attention to the connection with the practice teaching. Though we keep the class hours of curriculum theory stable, we must pay more attention to the directivity and depth of teaching content by using effective teaching approaches. The main approaches include: (1) developing internal relationship and systematicness of the teaching plans. (2) optimizing the balance between wide range of knowledge and crucial theoretical contents. (3) improving the prescription and actual effect of the teaching content.

Through the continuous improvement of the teaching process, we carefully choose teaching contents. Furthermore, professional teachers \& medical departments experts are both in our teamwork. The advantages of teachers teamwork from college and hospital have been brought into play a key role to improve the complementarity of teaching resources. Moreover, the experts in theory teaching are responsible for practice teaching after their classroom theory teaching. And it achieves a seamless connection between theory teaching and practice teaching. As shown in Table 2, under the unfavorable factors such as professional adjustment and school enrollment scale changing, the pass rate of final test has not been affected, and its trend has been steady. Meanwhile, the excellence rate has been improved. It shows that the teaching teamwork is stable and the teaching work has the characteristics of continuity and standardization. By analysing practice teaching achievement shown in Table 2, we also find the same trend that the average practice assessments can ascend year by year.

Table 2: Statistics on theory and practice achievements of the course

\begin{tabular}{|llll|}
\hline Academic years & Average achievement & Pass rate $\%$ & Excellent rate $\%$ \\
\hline 2014 & 78.4 & 98.0 & 18.0 \\
\hline 2015 & 78.4 & 96.0 & 32.0 \\
\hline 2016 & 82.6 & 96.6 & 31.0 \\
\hline 2017 & 83.1 & 97.8 & 37.5 \\
\hline
\end{tabular}

According to the $3 \mathrm{E}$ concept, it emphasizes that local native college should play a intelligent supporting role in regional economic industrial transformation and upgrading. To match local economic development needs and requirements of enterprise technology innovation, practice teaching should make full use of local resources. And also college should play its own advantages. By concising college specialty's teaching characteristics, we have deepen the integration of theory teaching and practice teaching. We have tried to improve the effectiveness of practicce teaching and to connect it with theoretical knowledge. Concrete practice teaching projects should be timely docked to crucial theory knowledge points. Moreover we must to designe to extend training time of the clinical significance or practical value of maintenance projects.
When it comes to student organization plan, the training process is standardized and managed, and the management documents and rules are issued and strictly implemented. In the outline, specific provisions for the purpose of training, organization and leadership, implementation methods, teaching contents, discipline requirements and assessment methods are put forward. For example, content in table 3 indicate the probation items, requirements and assessment methods specified in the outline. The method of evaluating the students' knowledge points and the comprehensive results after practice training is clearly listed in the outline, and the standard for the evaluation of the practical effect is quantified too. 
Table 3: Probation time and content requirements

\begin{tabular}{|c|c|c|}
\hline Probation items & Department(days) & content requirements \\
\hline $\begin{array}{l}\text { X-ray machine (CR, } \\
\text { DR,DSA) }\end{array}$ & $\begin{array}{l}\text { Radiology (2), } \\
\text { Interventional } \\
\text { radiology (2) }\end{array}$ & $\begin{array}{l}\text { 1. Understand the layout of the computer room and the design of the dark } \\
\text { room. } \\
\text { 2, master the knowledge of X-ray protection. } \\
\text { 3, master the basic composition and structure of CR, DR and DSA. } \\
\text { 4. Master the operation principle and principle of X - ray machine. } \\
\text { 5. Master the position, exposure conditions and darkroom techniques of each } \\
\text { part. } \\
\text { 6. Familiar with the common faults and maintenance of the X - ray machine. } \\
\text { 7. The difference between the traditional X - ray machine and the digital X - } \\
\text { ray imaging method. } \\
\text { 8, understand the clinical common disease, multi - incidence X-ray diagnosis. }\end{array}$ \\
\hline СТ & $\begin{array}{l}\text { Imaging Department } \\
(2), \\
\text { Interventional } \\
\text { radiology (2) }\end{array}$ & $\begin{array}{l}\text { 1. Familiar with the structure and layout of the CT room. } \\
\text { 2. Master the operation rules of CT. } \\
\text { 3. Understand the CT and daily maintenance. } \\
\text { 4. Master the indication of CT. } \\
\text { 5. Master the position of CT in each part. } \\
\text { 6. Understand the CT diagnosis of common diseases and multiple diseases. } \\
\text { 7. Understand the CT common faults and troubleshooting. } \\
\text { 8. Master the difference and enhancement method of plain scan and } \\
\text { enhanced scan. }\end{array}$ \\
\hline
\end{tabular}

In order to guide the practice of each semester, our teamwork has developed a detailed practice training plan based on the outline. In the plan, we further clarify the responsibilities of instructors including hospital staffs. Under the great cooperation of all aspects, practice has been achieved according to the general requirements of "where the equipment is, where people are", and achieved close contact between students and medical devices like X, CT and others. Since the beginning of this practice teaching reform, practice training has been strengthened. As shown in Table 2, compared with 78.4 points at beginning of the teaching reform, the average score of "teacher plus physician" professional practice teaching course has increased to 83.1 points, and the average student practical ability has been promoted to a good level.

\subsection{The quality and effect of training are feedbacked}

To assess the performance of theory teaching, teaching teamwork is responsible for this course's final test. The form of examination is a written and open-book test, which reflect the emphasis of theoretical knowledge and comprehensive analysis ability. From the review and examination of each semester, the examination result of the medical X-ray machine course is good and the excellent rate of the final test showed an upward trend (Table 2). It is reflected that after efficient theoretical and practical learning, the enthusiasm and self-confidence of curriculum study have been greatly improved. In our survey, the question item that professional teachers plus medical experts teaching mode is a favorite choice. The choice proportion of this item reached $83 \%$. When it comes to the items "Whether internship / probation is help for your study" and "Whether internship / probation have help on resolving doubt problems in the theory learning", the two options choice results also demonstrate that more than $88 \%$ of the students reflect to enhance the learning effect. Thus teaching and learning have been achieving a certain interaction.

Investigation activities are carried out in time after the end of each term. Through the questionnaire, "BMECamp" online survey in the WeChat, the students' opinion on practice training course, teaching processing, obtained skills and expected occupation planning are all timely appeared in survey data. The data are helpful to encourage teaching team to constantly optimize specific implementation methods and practice teaching design. It makes the course more adapting practice teaching goals and talent training needs.

\section{ACKNOWLEDGEMENT}

This teaching reform work was supported by innovation and strengthening university project of Guangdong pharmaceutical university and the construction project of Guangdong province quality engineering for characteristic specialty in 2016 ([2016]233). It was also supported by Guangdong province quality engineering for excellent talent training project in 2014 ([2014]97): exploration and practice onhe training mode of excellent engineers for medical instruments. And we also thank to the funding support of Guangdong pharmaceutical university education reform project (2015[15]): exploration and practice on the training mode of applied medical X-ray engineer.

\section{REFERENCE}

[1] Hu, B., Feng, H., Han, W.L., Xu, L. 2017. Speed up the construction of new engineering and promote the reform and innovation of Engineering Education- a summary of the Symposium on the development of engineering education in comprehensive universities. Fudan education forum, 15 (2), 20-27.

[2] Zhong, D.H. 2017. Connotation and action of emerging engineering education. Higher engineering education research, 3, 1-6.

[3] Lin. J. 2017. The construction of emerging engineering education for the future of China. Tsinghua university education research, 38 (2), 26-35.

[4] Chen, H., Chen, M. 2017. Thinking and exploring on the training of new engineering talents in comprehensive universities and colleges. Higher engineering education research, 2, 19-23.

[5] Zhu, X.F., Li, L.D., Song, H.L., Xu, J.Z., Dong, M., Li, Y.S. 2017. Practice teaching reform for biomedical engineering and medical imaging specialty. China health industry, 14 (28), 197-198. 